\title{
Severe Plasmodium knowlesi infection with multi-organ failure imported to Germany from Thailand/Myanmar
}

Michael Seilmaier ${ }^{1 *}$, Wulf Hartmann², Marcus Beissner ${ }^{3}$, Thomas Fenzl ${ }^{1}$, Cathrine Haller ${ }^{2}$, Wolfgang Guggemos ${ }^{1}$, Jan Hesse ${ }^{2}$, Adinda Harle ${ }^{3}$, Gisela Bretzel ${ }^{3}$, Stefan Sack², Clemens Wendtner ${ }^{1}$, Thomas Löscher ${ }^{3}$ and Nicole Berens-Riha ${ }^{3}$

\begin{abstract}
During the last two decades human infections with Plasmodium knowlesi are increasingly diagnosed in South East Asia and have also been reported in travellers. A severe case of imported P. knowlesi infection in a 73-year old German is presented, who had been travelling through Myanmar and Thailand for three weeks. Microscopy showed a parasitaemia of $3 \%$ and different parasite stages including band-forms resembling Plasmodium malariae. Due to the clinical picture of severe malaria and the microscopical aspect (combination of parasites resembling $P$. malariae and Plasmodium falciparum), P. knowlesi was suspected. The patient was treated with intravenous quinine; he was put on mechanical ventilation and catecholamines due to cardiorespiratory failure. Parasitaemia was cleared rapidly but renal function deteriorated resulting in intermittent haemodialysis. The patient was hospitalized for six weeks but he recovered completely without any physical sequelae. Plasmodium knowlesi mono-infection was confirmed by molecular methods later on.

Plasmodium knowlesi infection has to be taken into account in feverish travellers returning from Thailand/Myanmar. Moreover this species can cause life-threatening or even lethal complications. Accordingly severe $P$. knowlesi infection should be treated like severe $P$. falciparum infections.
\end{abstract}

Keywords: Plasmodium knowlesi, Imported malaria, Severe malaria, Multi-organ failure

\section{Background}

A severe case of Plasmodium knowlesi infection in a 73year old man who had been travelling three weeks through Burma and southern Thailand in November/December 2013 is described.

According to published cases, this is the third imported infection with $P$. knowlesi to Germany and the most severe described so far. The severe course of the disease was likely due to delayed medical presentation by the patient and thus diagnosis could only be established seven days after onset of symptoms.

Plasmodium knowlesi is known since the early 1930, it affects macaques endemic in Southeast Asia and it has

\footnotetext{
* Correspondence: michael.seilmaier@klinikum-muenchen.de 'Department of Haematology, Oncology, Immunology, Palliative Care, Infectious Diseases and Tropical Medicine, Klinikum Schwabing, Akademisches Lehrkrankenhaus der Ludwig-Maximilians-Universität, Kölner Platz 1, 80804 Munich, Germany

Full list of author information is available at the end of the article
}

been named in honour of Robert Knowles (1883-1936; School of Tropical Medicine and Hygiene/Calcutta). Knowles first described this Plasmodium species in 1930 and he even showed the capacity of artificial human infection with subsequent malaria symptoms. During the last two decades, human P. knowlesi cases are found more and more often in many countries in Southeast Asia.

\section{Case presentation}

The 73-year old German patient had been travelling in December 2013 for three weeks for diving and rainforest excursions; he visited the island of Mecleod (Myanmar) and in Thailand Khura Buri, the island Koh Ra, Khao Lak, and Phuket. The day after his return, he developed high fever and chills. He had not taken anti-malarial chemoprophylaxis. After five days with high fever at home (six days after returning from Southeast-Asia), the
() Biomed Central 
patient presented to his general practitioner who referred him immediately to the nearest hospital.

On admission, the patient was already hypotonic and in respiratory distress with signs of somnolence (GSCS $7-8$, RR $70 / 50 \mathrm{mmHg}$, pulse $115 / \mathrm{min}$ respiratory frequency $18-20 / \mathrm{min}$, temperature $39,4^{\circ} \mathrm{C}, \mathrm{SPO}_{2} 74 \%$ ). Due to symptoms of shock, decreased gas exchange $(\mathrm{pH} 7,28$, HC03 $18 \mathrm{mmol} / \mathrm{l}$ ) and pulmonary distress (tachypnoea), the patient was put on mechanical ventilation. Catecholamines had to be administered to maintain sufficient perfusion and circulation. Initially, sepsis due to a urinary tract infection was suspected and antibiotic therapy with ciprofloxacin was initialized. However, the patient's condition deteriorated rapidly and piperacillin/sulbactam were added to the antibiotic regimen. As the thrombocyte count dropped dramatically $(30,000 / \mathrm{nl})$, malaria infection was suspected. The Department of Infectious Diseases and Tropical Medicine at Schwabing Hospital in Munich was contacted and the patient was transferred to its ICU via helicopter.

On a moderate dosage of catecholamines $(0.4 \mu \mathrm{g}$ arterenol/min), vital parameters were stable. Laboratory parameters are displayed in Tables 1 and 2. Ventilation was performed with $50 \%$ oxygen and a PEEP of $8 \mathrm{~cm} \mathrm{H}_{2} \mathrm{O}$ in BIPAP modus. Abdominal ultrasound showed a slight splenomegaly (15 cm diameter at the hilus) and small bilateral pleural effusions. The chest $\mathrm{x}$-ray at the first day showed beginning ARDS (interstitial opacities, small pleural effusions and congestion), chest $\mathrm{x}$-ray four days later showed bilateral basal infiltrations.

Thin blood smears revealed 3\% parasitaemia. The trophozoites resembled Plasmodium falciparum and Plasmodium malariae. Band-forms and gametocytes reminded of P. malariae (Figure 1).

Plasmodium knowlesi infection was, therefore, suspected and therapy started with intravenous quinine (due to the lack of artesunate at the time of diagnosis) in combination with doxycycline (200 mg per day) immediately upon arrival at the intensive care unit (ICU) of Schwabing hospital. The patient showed a quick response to quinine and was completely cleared from parasites within 48 hours. A subsequently developed ventilatorassociated pneumonia was treated successfully with meropenem. Creatinine and glomerular filtration rate (GFR) were already impaired on admission and acute anuric kidney failure developed within the first day (Table 1). The patient needed haemodialysis for five weeks but the kidney function finally recovered and the patient could be discharged without sequelae.

The severe course of the disease with malaria-related lung and kidney failure was likely due to delayed medical presentation by the patient and thus diagnosis could only be established seven days after onset of symptoms.

Definite diagnosis was confirmed by PCR (DITM). A Plasmodium genus-specific real-time PCR was positive but the multiplex PCR for the other four human Plasmodium species was negative (FTD Malaria, Mikrogen Diagnostik, Neuried, Germany). Two P. knowlesi-specific nested PCRs based on the 18S rRNA gene showed the expected amplicons [1,2]. Direct DNA sequencing of PCR products confirmed 99\% nucleotide concordance with P. knowlesi strains from Thailand and Malaysia.

Written informed consent of the patient was procured for publication.

\section{Discussion}

Plasmodium knowlesi is known since the early 1930 as a parasite of macaques endemic in Southeast Asia [3]. In 1965, naturally acquired human infection was first reported in an American tourist travelling through Malaysia [4]. Retrospectively, Singh et al. recently detected a high prevalence of $P$. knowlesi in humans in East Malaysia but it still seems to be under-diagnosed due to diagnostic constraints and possibly also due to a lack of awareness concerning this Plasmodium species [2,5-7].

In certain areas of Malaysia (Sarawak, Borneo), the prevalence of human P. knowlesi was as high as 50\%, whereas in Thailand it was around $1 \%[1,8-11]$. Human P. knowlesi infections were observed so far in Malaysia, Thailand, Burma, Vietnam, the Philippines, Singapore, and Indonesia [12]. As a travel-related disease it was still rarely described $[5,6,12]$. This is the third documented case in Germany and the number of infections in other non-endemic countries is likewise low $[4,5,11]$.

Along with better diagnostic tools and awareness raising, an increase of $P$. knowlesi infections in humans during the last two decades is discussed and might be attributable to a reduction of the natural habitat of

Table 1 Important laboratory parameters

\begin{tabular}{|c|c|c|c|c|c|c|}
\hline $\begin{array}{l}\text { Parameter } \\
\text { (normal range) }\end{array}$ & $\begin{array}{l}\text { Creatinine } \\
(0.7-1.2 \mathrm{mg} / \mathrm{dL})\end{array}$ & $\begin{array}{l}\text { GFR } \\
(>60 \mathrm{~mL} / \mathrm{min})\end{array}$ & $\begin{array}{l}\text { Procalcitonin } \\
(<0.5 \mu \mathrm{g} / \mathrm{L})\end{array}$ & $\begin{array}{l}\text { CRP } \\
(<5 \mathrm{mg} / \mathrm{L})\end{array}$ & $\begin{array}{l}\text { LDH } \\
(125-220 \mathrm{U} / \mathrm{L})\end{array}$ & $\begin{array}{l}\text { Bilirubin } \\
(0,2-1,2 \mathrm{mg} / \mathrm{dL})\end{array}$ \\
\hline Day 1 & 1.7 & 40 & 32.4 & 300.2 & 415 & 1.4 \\
\hline Day 2 & 3.1 & 19 & 38.7 & 342.6 & 586 & 2.2 \\
\hline Day 5 & $5.1(\mathrm{HD})$ & 11 & 8.2 & 149 & 924 & 1.5 \\
\hline Day 30 & 1.9 & 32 & 0,1 & 5.8 & 391 & 0.8 \\
\hline
\end{tabular}

Bold means pathological values. 
Table 2 Blood count over time

\begin{tabular}{|c|c|c|c|c|}
\hline $\begin{array}{l}\text { Parameter } \\
\text { (normal range) }\end{array}$ & $\begin{array}{l}\text { Erythrocyte count } \\
(4.5-5.9 / \mathrm{pL})\end{array}$ & $\begin{array}{l}\text { Haemoglobin } \\
(13.5-17 \mathrm{~g} / \mathrm{dL})\end{array}$ & $\begin{array}{l}\text { Thrombocyte count } \\
(140-360 / \mathrm{nL})\end{array}$ & $\begin{array}{l}\text { Leucocyte count } \\
(3.5-9.8 / \mathrm{nL})\end{array}$ \\
\hline Day 1 & 3.7 & 11.3 & 39 & 8.8 \\
\hline Day 2 & 3.7 & 10.9 & 86 & 11.1 \\
\hline Day 5 & 2.7 & 8.0 & 153 & 25.2 \\
\hline Day 30 & 3.2 & 9.8 & 391 & 5.7 \\
\hline
\end{tabular}

Bold means pathological values.

macaques, the invasion of humans into rainforests (e g, for economical reasons) and an increasing number of the Anopheles vectors feeding on both humans and monkeys [11].

The main vectors for P. knowlesi, Anopheles cracens and Anopheles lateens, feed on macaques as well as on humans [11]. Also, the predominantly antropophilic Anopheles stephensi which is widely distributed in Southeast Asia, can be easily infected with P. knowlesi, and were found in rural as well as urban areas [13]. Most reported cases of $P$. knowlesi had visited rainforest
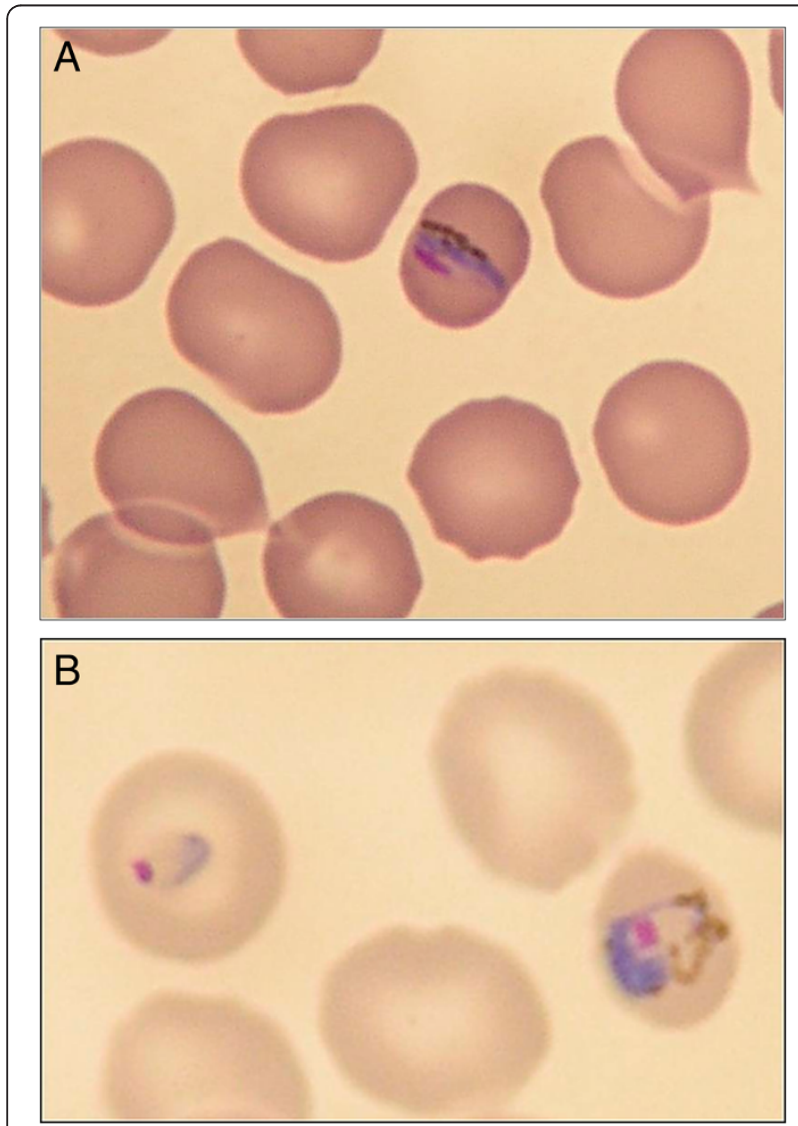

Figure 1 Microscopic aspect of Plasmodium knowlesi in a blood smear of the presented case prior to initiation of treatment with quinine. (A) Band form late trophozoite; (B) Early trophozoite or ring form (left) and late trophozoite (right). regions prior to manifestation of malaria [14]. So far only one case reported in the medical literature describes a $P$. knowlesi infection without prior rainforest excursions [14]. This indicates a direct link to the natural habitat of $P$. knowlesi. So far, there is no evidence of a stable human-Anopheles-human transmission [6]. The patient presented in this report most probably contracted the infection in southern Thailand. Ranong province was also the probable site of infection in two other German $P$. knowlesi cases published so far $[15,16]$.

Plasmodium knowlesi may take a severe, even fatal course, such as described for P. falciparum infections, in about $7 \%$, as $P$. knowlesi can lead to hyperparasitaemia [5,17]. Like P. falciparum, P. knowlesi can invade all erythrocytes, not only very young erythrocytes as in Plasmodium vivax and Plasmodium ovale, or very mature erythrocytes as in P. malariae [5]. Moreover, the intra-erythrocytic cycle lasts only 24 hours, which is much shorter than in any other human malaria species and this can lead to a rapid progression of $P$. knowlesi infection [5,13].

Therefore, immediate initiation of treatment and vigilant clinical observation is essential. As $P$. knowlesi has no liver hypnozoite stage the infection does not relapse [5]. Nevertheless, there are cases of complicated malaria due to $P$. knowlesi with renal failure and respiratory distress in patients with low parasitaemia [15]. On the other hand, data indicate asymptomatic infection as well $[1,6]$.

The presented patient faced a severe, life-threatening course of the disease with 3\% parasitaemia.

He developed complete anuric kidney failure, impaired consciousness, respiratory distress and circulatory deficits, and therefore needed mechanical ventilation and catecholamines shortly after hospital admission. In this case, initial suspicion of a $P$. knowlesi infection was based on the detection of intra-erythrocytic ring forms which resembled $P$. falciparum as well as band forms and schizonts indistinguishable from $P$. malariae in the patient's thin blood smear. This is a typical aspect of $P$. knowlesi infection and, therefore, P. knowlesi is prone to misidentification and needs further confirmation by means of PCR $[1,6]$.

The laboratory results often reveal a significant to severe thrombocytopaenia, signs of haemolysis with anaemia, and elevated liver enzymes, like as in this patient. A close 
correlation between $P$. knowlesi parasitaemia and platelet count is assumed and it seems that the degree of the thrombocytopaenia could be even worse than in other types of malaria [8]. However, it usually quickly improves with successful parasite clearance $[18,19]$.

Other important signs of a life-threatening situation in a P. knowlesi infection are: acidosis, rapid drop in erythrocyte count, jaundice, renal impairment or even renal failure, respiratory distress, and hypotonia $[5,18,20]$. Patients with impaired consciousness and decreased Glasgow Coma Scores have been described in severe and fatal cases but other signs and symptoms such as unrousable coma did not satisfy the WHO criteria for cerebral malaria [20]. Pathological brain alterations in a fatal case of human $P$. knowlesi malaria were similar to those found in P. falciparum malaria with multiple petechial haemorrhages and sequestration of pigmented parasitized red blood cells in capillaries and venules. However, unlike in falciparum malaria ICAM 1 (intracellular-adhesion-molecule) was not found to be up-regulated, therefore the pathophysiological aspects seem to be different [21].

Undoubtedly the patient suffered from severe malaria corresponding with the WHO classification and his altered mental status (GSCS 7-8) suggests cerebral involvement. The patient had anuric kidney and lung failure, severe haemolysis and cerebral impairment qualifying him for severe malaria with multiorgan failure (apart from the hyperparasitaemia).

Autoptic changes in the lung tissue of a patient who had died from $P$. knowlesi malaria suggest that lung injury occurs in non-falciparum-malaria and ARDS has to be taken into account [21].

Moreover a case series of five patients who died from knowlesi malaria in Malaysia showed that pulmonary problems and respiratory distress were quite common in this infection [22].

So far there is no standard treatment protocol for $P$. knowlesi malaria based on RCTs but it seems that most of the anti-malarial drugs are effective $[6,13]$. However, one case report showed an increase in parasitaemia after application of mefloquine as a possible hint for resistance [13]. Both parenteral quinine and artemisinins have been effective in the treatment of severe $P$. knowlesi malaria [20]. Current WHO guidelines recommend artesunate i.v. as a first choice in treating severe malaria caused by all plasmodium species as the clearance of parasites is rapid with less side-effects [8,20,22-24]. Since parenteral artemisinin were not readily available, the patient presented was treated with quinine per infusionem and showed a rapid clearance of parasitaemia.

\section{Conclusion}

Infection due to $P$. knowlesi has to be taken into account in feverish patients returning from Southeast Asia (namely from Malaysia, Borneo and Ranong Province in Thailand), especially when the parasites in malaria blood slides have close resemblance to $P$. malariae and/or $P$. falciparum. PCR diagnosis is crucial for definite characterization of $P$. knowlesi as microscopic differentiation is hardly possible. As a travel related disease P. knowlesi malaria is still highly exceptional with only a small number of cases reported every year from non-endemic, western countries. Plasmodium knowlesi may cause a rapid clinical deterioration as the intra-erythrocytic cycle is only 24 hours and in almost $7 \%$ it has a severe, life-threatening course with multiorgan failure (such as in P. falciparum malaria). Correspondingly, severe $P$. knowlesi malaria should be treated like severe $P$. falciparum malaria.

\section{Competing interests}

The authors have declared that they have no competing interests.

\section{Authors' contributions}

MS supervised treatment of the patient and drafted the manuscript. $\mathrm{WH}, \mathrm{CH}$, $\mathrm{JH}$, and SS treated the patient in ICU. TF, WG and MB treated the patient until discharge. $\mathrm{GB}$ and $\mathrm{AH}$ were responsible for the laboratory diagnostic. $\mathrm{TL}$ helped drafting the manuscript. NBR performed the molecular diagnostic and drafted the manuscript. All authors read and corrected the manuscript.

\section{Author details}

${ }^{1}$ Department of Haematology, Oncology, Immunology, Palliative Care, Infectious Diseases and Tropical Medicine, Klinikum Schwabing, Akademisches Lehrkrankenhaus der Ludwig-Maximilians-Universität, Kölner Platz 1, 80804 Munich, Germany. ²Department of Cardiology, Pneumology, and Intensive Care Medicine, Klinikum Schwabing, Akademisches Lehrkrankenhaus der Ludwig-Maximilians-Universität, Kölner Platz 1, 80804 Munich, Germany. ${ }^{3}$ Department of Infectious Diseases and Tropical Medicine (DITM), University Hospital, Ludwig-Maximilians-University, Leopoldstrasse 5, 80802 Munich, Germany.

Received: 14 April 2014 Accepted: 8 July 2014

Published: 4 November 2014

\section{References}

1. Singh B, Kim Sung L, Matusop A, Radhakrishnan A, Shamsul SS, Cox-Singh J, Thomas A, Conway DJ: A large focus of naturally acquired Plasmodium knowlesi infections in human beings. Lancet 2004, 363:1017-1024.

2. Imwong M, Tanomsing N, Pukrittayakamee S, Day NP, White NJ, Snounou G: Spurious amplification of a Plasmodium vivax small-subunit RNA gene by use of primers currently used to detect P. knowlesi. J Clin Microbiol 2009, 47:4173-4175.

3. Knowles RM, Das Gupta B: A study of monkey-malaria and its experimental transmission to man. Ind Med Gaz 1932, 67:301-320.

4. Chin W, Contacos PG, Coatney GR: A naturally acuited quotidian type malaria in man transferable to monkeys. Science 1965, 149:865.

5. Cox-Singh J, Davis TM, Lee KS, Shamsul SS, Matusop A, Ratnam S, Conway DJ, Singh B: Plasmodium knowlesi malaria in humans is widely distributed and potentially life threatening. Clin Infect Dis 2008, 46:165-171.

6. Azira NM, Zairi NZ, Amry AR, Zeehaida M: Case series of naturally acquired Plasmodium knowlesi infection in a tertiary teaching hospital. Trop Biomed 2012, 29:398-404.

7. Sulistyaningsih E, Fitri LE, Löscher T, Berens-Riha N: Diagnostic difficulties with Plasmodium knowlesi infection in humans. Emerg Infect Dis 2010, 16:1033-1034.

8. Barber BE, William T, Grigg MJ, Menon J, Auburn S, Marfurt J, Anstey NM, Yeo TW: A prospective comparative study of knowlesi, falciparum, and vivax malaria in Sabah, Malaysia: high proportion with severe disease from Plasmodium knowlesi and Plasmodium vivax, but no mortality with early referral and artesunate therapy. Clin Infect Dis 2013, 56:383-397.

9. Lau YL, Tan LH, Chin LC, Fong MY, Noraishah MA, Rohela M: Plasmodium knowlesi reinfection in human. Emerg Infect Dis 2011, 17:1314-1315. 
10. Sermwittayawong N, Singh B, Nishibuchi M, Sawangjaroen N, Vuddhakul V: Human Plasmodium knowlesi infection in Ranong province, southwestern border of Thailand. Malar J 2012, 11:36.

11. Vythilingam I, Noorazian YM, Huat TC, Jiram A, Yusri YM, Azahari AH, Norparina I, Noorrain A, Lokmanhakim S: Plasmodium knowlesi in humans, macaques and mosquitoes in peninsular Malaysia. Parasit Vectors 2008, 1:26.

12. Kantele A, Jokiranta TS: Review of cases with the emerging fifth human malaria parasite, Plasmodium knowlesi. Clin Infect Dis 2011, 52:1356-1362.

13. Fatih FA, Staines HM, Siner A, Ahmed MA, Woon LC, Pasini EM, Kocken CH, Singh B, Cox-Singh J, Krishna S: Susceptibility of human Plasmodium knowlesi infections to anti-malarials. Malar J 2013, 12:425.

14. Berry A, lriart X, Wilhelm N, Valentin A, Cassaing S, Witkowski B, Benoit-Vical F, Menard S, Olagnier D, Fillaux J, Sire S, Le Coustumier A, Magnaval JF: Imported Plasmodium knowlesi malaria in a French tourist returning from Thailand. Am J Trop Med Hyg 2011, 84:535-538.

15. Ehrhardt J, Trein A, Kremsner PG, Frank M: Plasmodium knowlesi and HIV coinfection in a German traveller to Thailand. Malar J 2013, 12:283.

16. Orth $\mathrm{H}$, Jensen $\mathrm{BO}$, Holtfreter MC, Kocheril SJ, Mallach S, MacKenzie C, Müller-Stöver I, Henrich B, Imwong M, White NJ, Häussinger D, Richter J: Plasmodium knowlesi infection imported to Germany, January 2013. Euro Surveill 2013, 18:20603.

17. Lee WC, Chin PW, Lau YL, Chin LC, Fong MY, Yap CJ, Supramaniam RR, Mahmud R: Hyperparasitaemic human Plasmodium knowlesi infection with atypical morphology in peninsular Malaysia. Malar J 2013, 12:88.

18. Daneshvar C, Davis TM, Cox-Singh J, Rafa'ee MZ, Zakaria SK, Divis PC, Singh B: Clinical and laboratory features of human Plasmodium knowlesi infection. Clin Infect Dis 2009, 49:852-860.

19. Willmann M, Ahmed A, Siner A, Wong IT, Woon LC, Singh B, Krishna S, Cox-Singh J: Laboratory markers of disease severity in Plasmodium knowlesi infection: a case control study. Malar J 2012, 11:363.

20. William T, Menon J, Rajahram G, Chan L, Ma G, Donaldson S, Khoo S, Frederick C, Jelip J, Anstey NM, Yeo TW: Severe Plasmodium knowlesi malaria in a tertiary care hospital, Sabah, Malaysia. Emerg Infect Dis 2011, 17:1248-1255.

21. Cox-Singh J, Hiu J, Lucas SB, Divis PC, Zulkarnaen M, Chandran P, Wong KT, Adem P, Zaki SR, Singh B, Krishna S: Severe malaria-a case of fatal Plasmodium knowlesi infection with post-mortem findings: a case report. Malar J 2010, 9:10.

22. Rajahram GS, Barber BE, William T, Menon J, Anstey NM, Yeo TW: Death due to Plasmodium knowlesi malaria in Sabah, Malaysia: association with reporting as Plasmodium malariae and delayed parenteral artesunate. Malar J 2012, 11:284.

23. Vadivelan M, Dutta T: Recent advances in the management of Plasmodium knowlesi infection. Trop Parasitol 2014, 4:31-34.

24. World Health Organisation: Management of severe malaria - A practical handbook. 3rd edition. WHO; 2012 [http://www.who.int/malaria/publications/ atoz/9789241548526/en/

doi:10.1186/1475-2875-13-422

Cite this article as: Seilmaier et al: Severe Plasmodium knowlesi infection with multi-organ failure imported to Germany from Thailand/Myanmar. Malaria Journal 2014 13:422.

\section{Submit your next manuscript to BioMed Central and take full advantage of:}

- Convenient online submission

- Thorough peer review

- No space constraints or color figure charges

- Immediate publication on acceptance

- Inclusion in PubMed, CAS, Scopus and Google Scholar

- Research which is freely available for redistribution

Submit your manuscript at www.biomedcentral.com/submit
C Biomed Central 